\title{
Turbulence Amplification with Incidence at the Leading Edge of a Compressor Cascade
}

\author{
GARTH V. HOBSON ${ }^{\mathrm{a}, *}$, BRYCE E. WAKEFIELD ${ }^{\mathrm{a}}$ and WILLIAM B. ROBERTS ${ }^{\mathrm{b}}$ \\ ${ }^{a}$ Code AA/Hg, Department of Aeronautics and Astronautics, Naval Postgraduate School, 699 Dyer Rd, Rm 137, \\ Monterey, CA 93943-5106, USA; ${ }^{\mathrm{b}}$ Flow Application Research Fremont, California, USA
}

(Received 28 October 1997; In final form 19 March 1998)

\begin{abstract}
Detailed measurements, with a two-component laser-Doppler velocimeter and a thermal anemometer were made near the suction surface leading edge of controlled-diffusion airfoils in cascade. The Reynolds number was near 700,000 , Mach number equal to 0.25 , and freestream turbulence was at $1.5 \%$ ahead of the cascade.

It was found that there was a localized region of high turbulence near the suction surface leading edge at high incidence. This turbulence amplification is thought to be due to the interaction of the free-shear layer with the freestream inlet turbulence. The presence of the local high turbulence affects the development of the short laminar separation bubble that forms very near the suction side leading edge of these blades. Calculations indicate that the local high levels of turbulence can cause rapid transition in the laminar bubble allowing it to reattach as a short "non-burst" type.

The high turbulence, which can reach point values greater than $25 \%$ at high incidence, is the reason that leading edge laminar separation bubbles can reattach in the high pressure gradient regions near the leading edge. Two variations for inlet turbulence intensity were measured for this cascade. The first is the variation of maximum inlet turbulence with respect to inlet-flow angle; and the second is the variation of leading edge turbulence with respect to upstream distance from the leading edge of the blades.
\end{abstract}

Keywords: Compressors, Boundary layers, Separation bubbles, Laser-Doppler velocimetry

\section{INTRODUCTION}

While experimental research was being conducted on the Sanger cascade blades at high inlet-air angles in the cascade wind tunnel of the Naval Postgraduate School (Sanger and Shreeve, 1986), complementary calculations, which were initially unsuccessful, were performed in an attempt to predict the off-design performance. Flow visualization studies by Sanger and Shreeve, at chord Reynolds number of 340,000 , indicated the presence of a laminar separation bubble near the

\footnotetext{
*Corresponding author. E-mail: garth $@$ aa.nps.navy.mil.
} 
leading edge. The cascade geometry was documented in Elazar and Shreeve (1989), and was the same geometry used for the calculations. The viscous flow features of this cascade are shown in Fig. 1.

Testing by Hobson and Shreeve (1993) indicated that at a very high inlet-flow angle $\left(\beta_{1}=48.4^{\circ}\right)$ the turbulence intensity right at the leading edge was amplified for the Sanger cascade. This could explain how a laminar separation bubble would be able to reattach as a short bubble in the steep pressure gradient near the leading edge at high incidence.

A deeper understanding of this phenomenon is desirable so as to correctly compute the boundary layer development in the leading edge, especially for compressor blades operating near stall. This is not only true for relatively simple inviscid-viscous methods, but also for full Navier-Stokes calculations. To gain a greater understanding of this phenomenon, detailed LDV measurements were made in the leading edge region of the Sanger cascade for inlet-flow angles of $\beta_{1}=43.3^{\circ}, 46.4^{\circ}$ and $48.4^{\circ}$. The order of magnitude of the leading edge turbulence amplification, which was significant at high incidence, was confirmed by thermal anemometer measurements at $\beta_{1}=48.4^{\circ}$.

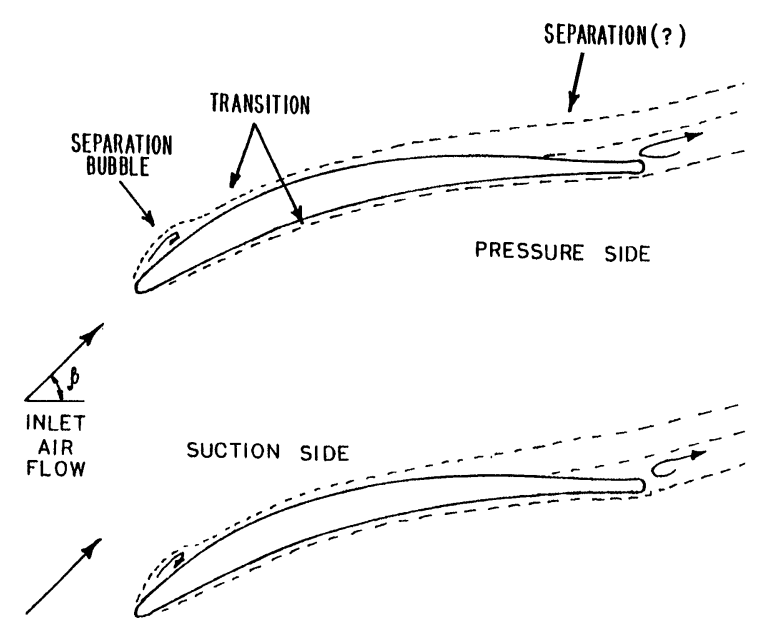

FIGURE 1 Viscous Flow features of the Sanger cascade (Elazar and Shreeve, 1989).

\section{DESCRIPTION OF THE PHYSICS AND ANALYSIS TECHNIQUE}

An inviscid-viscous scheme was used for the subsonic calculations (Martensen, 1959; LeFoll, 1965; Roberts, 1975). It was found that during the calculation the inviscid-viscous method predicted a "burst" laminar separation bubble very near the leading edge for $\beta_{1} \geq 38^{\circ}$, while the data of Sanger and Shreeve (1986) indicated the presence of a short bubble. Figure 2 shows a schematic of a short laminar separation bubble. A short laminar bubble "bursts" into a long bubble when reattachment is not possible in the short state, see Fig. 3 (for a description of the flow regimes possible with varying Reynolds number see, Roberts, 1975). As can be seen from Fig. 4 the suction surface velocity distribution is reasonably well predicted by the inviscid code. Since a long or "burst" laminar separation bubble by definition causes a significant change from the inviscid velocity distribution, which results in a decrease in the suction peak, this implies that the bubble present on the blade will be short.

As stated above the application of the boundary layer method predicted that the leading edge laminar separation bubble would not reattach The Reynolds number and freestream turbulence intensity $(\mathrm{Tu}=1.5 \%)$ were taken from upstream test conditions as given by Elazar and Shreeve (1989). The inviscid-viscous method was calibrated by Roberts (1975) for short and long mid-chord laminar separation bubbles, and for freestream turbulence intensities between $\sim 0 \%$ and $5 \%$. The method has been successfully applied to short bubbles found near the leading edge of a large chord wing model $(\sim 1.2 \mathrm{~m})$ of an NACA $66_{1} 3-018$ section, which was experimentally measured by Gault (1955) in a low turbulence wind tunnel.

The only mechanism that affects transition in a laminar bubble, for a fixed geometry and Reynolds number, is the local turbulence level. The length of the laminar part of the bubble is decreased for an increased value of local freestream turbulence. Therefore, very high local turbulence could cause 

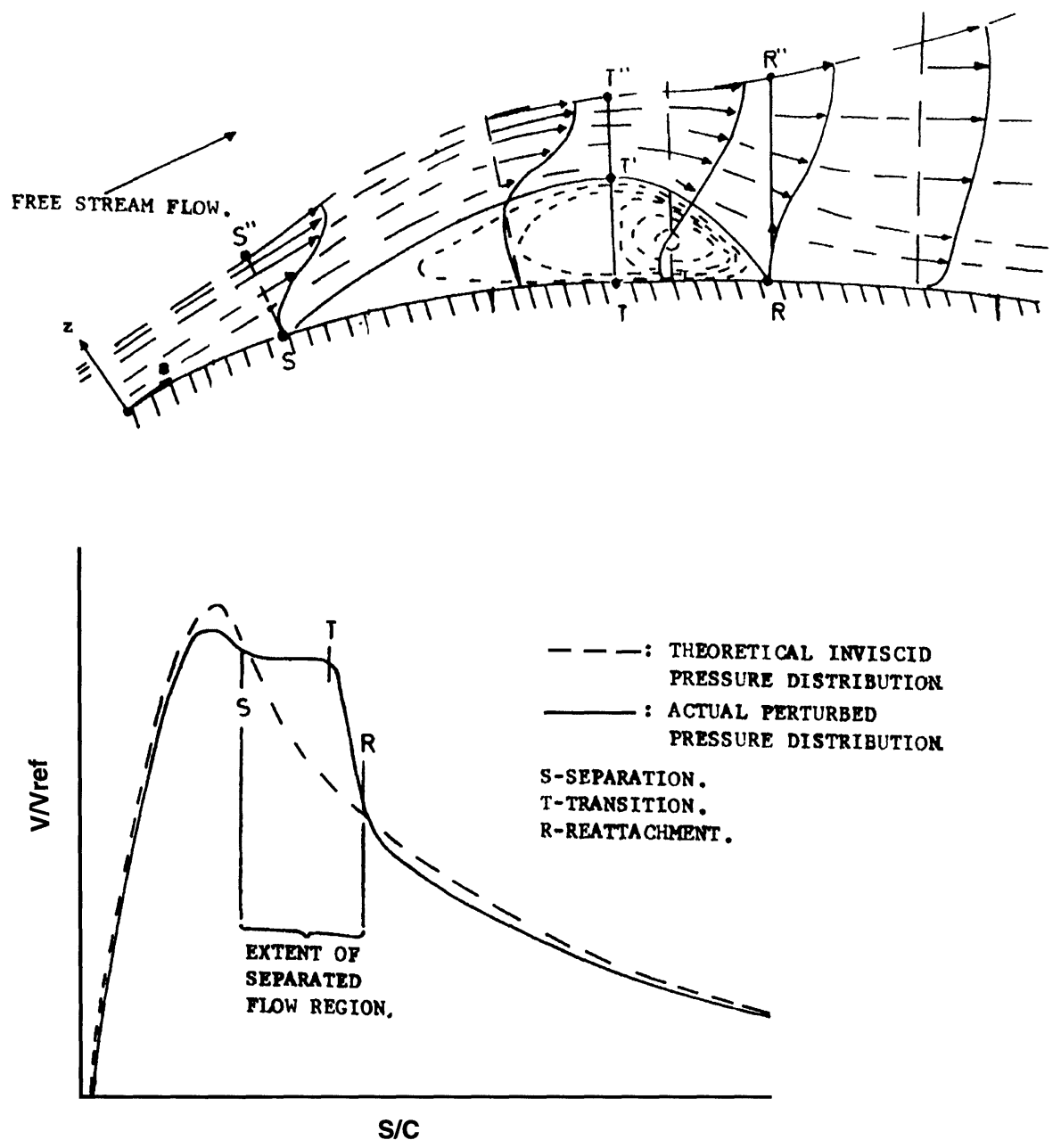

FIGURE 2 Sectional view of a two-dimensional short laminar separation bubble and corresponding surface velocity distribution.

rapid transition after separation allowing short bubble reattachment even in a severe pressure gradient. Additional calculations were performed for $\beta_{1}=40^{\circ}, 43.3^{\circ}$ and $46.4^{\circ}$ and compared to the laminar bubble reattachment locations reported by Sanger and Shreeve (1986). These were determined from flow visualization studies performed at a Reynolds number of 340,000 . For the calculations the experimental velocity distribution was used for the three inlet-air angles mentioned above. This was done to ensure that the laminar boundary layer was properly calculated so as to correctly locate the laminar separation point.
At first the freestream turbulence of $\mathrm{Tu}=1.5 \%$ was used in the calculations resulting in the prediction of "burst" bubbles. The turbulence level was then increased in subsequent calculations until short bubble reattachment occurred for each inletair angle. Finally, the turbulence level was further increased until the reattachment location agreed with the experimental data. This is shown in Fig. 5 where the turbulence required to match the data is indicated: $\mathrm{Tu}=8.5 \%$ for $\beta_{1}=40^{\circ}, \mathrm{Tu}=9.0 \%$ for $\beta_{1}=43.3^{\circ}$ and $\mathrm{Tu}=11.0 \%$ for $\beta_{1}=46.4^{\circ}$. Not only does this indicate that at medium to high incidence the leading edge turbulence is amplified, but that 


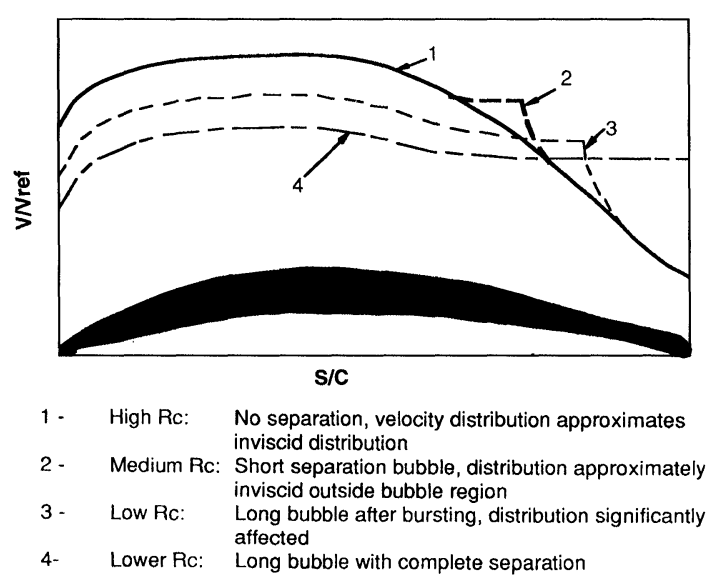

FIGURE 3 Schematic of four flow regimes possible with varying Reynolds number $\left(10^{4}-10^{6}\right)$ over the suction surface of a compressor profile (Roberts, 1975).

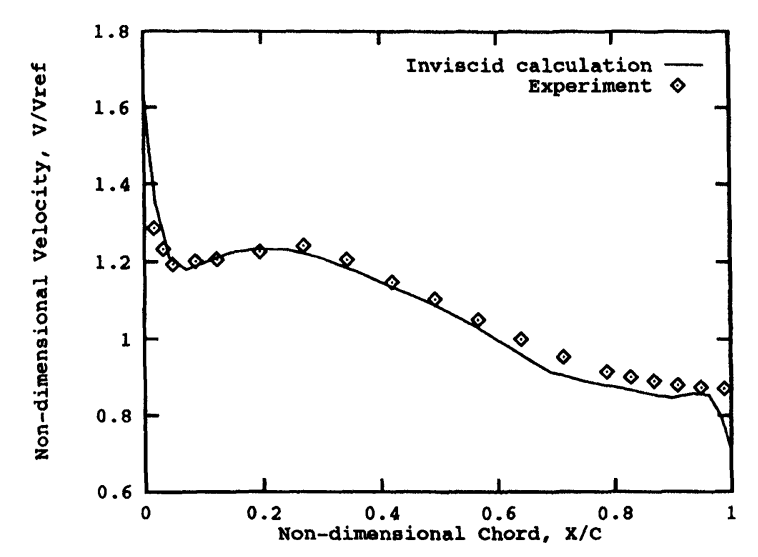

FIGURE 4 Suction surface velocity comparison $\beta_{1}=40^{\circ}$.

the level of turbulence is also a positive function of incidence.

\section{TEST FACILITY AND INSTRUMENTATION}

The experiments were performed in the Low Speed Cascade Wind Tunnel (LSCWT) at the Turbopropulsion Laboratory of the Naval Postgraduate School, which is shown schematically in Fig. 6. For a more detailed description of the facility see Sanger and Shreeve (1986). The LDV measurements

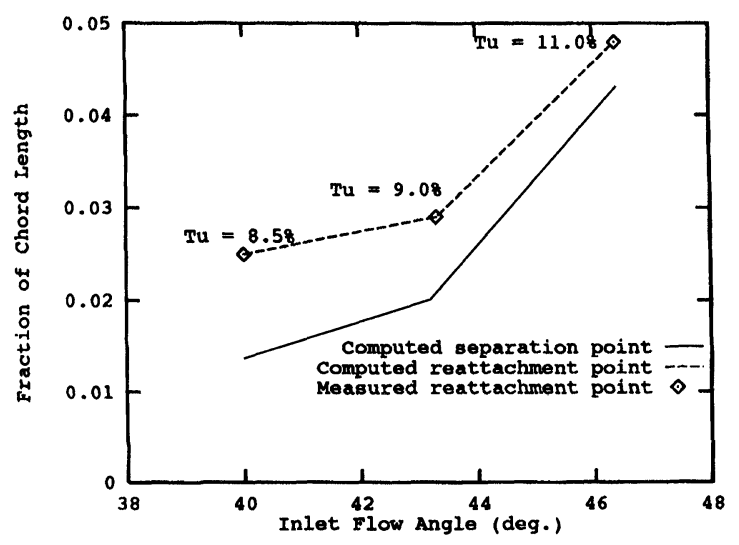

FIGURE 5 Separation bubble reattachment for various turbulence intensities $(\operatorname{Re}=340,000)$.

were performed with a two-component system, which is fully described by Elazar and Shreeve (1989). Figure 6 also shows the location of the introduction of seeding into the bellmouth of the tunnel, the profile coordinates of the Sanger Blade, and the cascade geometry and inlet conditions.

A $20 \mu \mathrm{m}$ (sensor diameter) hot-film probe, which had a sensor length of $1 \mathrm{~mm}$, was used with a TSI single channel hot-wire anemometer system (IFA100 and -200) connected to a personal computer. A complete description of the hot-film instrumentation is given by Wakefield (1993).

\section{EXPERIMENTAL PROCEDURE}

Inlet pitchwise LDV surveys were performed ahead of the leading edge of the blades for three different inlet-flow angles $\left(43.3^{\circ}, 46.4^{\circ}\right.$ and $\left.48.4^{\circ}\right)$. The six axial locations of the survey planes and respective orientation of the LDV were the same as those described by Hobson and Shreeve (1993). In their study, they performed detailed measurements upstream, downstream and through the passage of the blade row including around the leading edge separation bubble at the high inlet-flow angle of $48.4^{\circ}$.

Hot-film surveys were performed at the three survey planes which were closest to the leading 


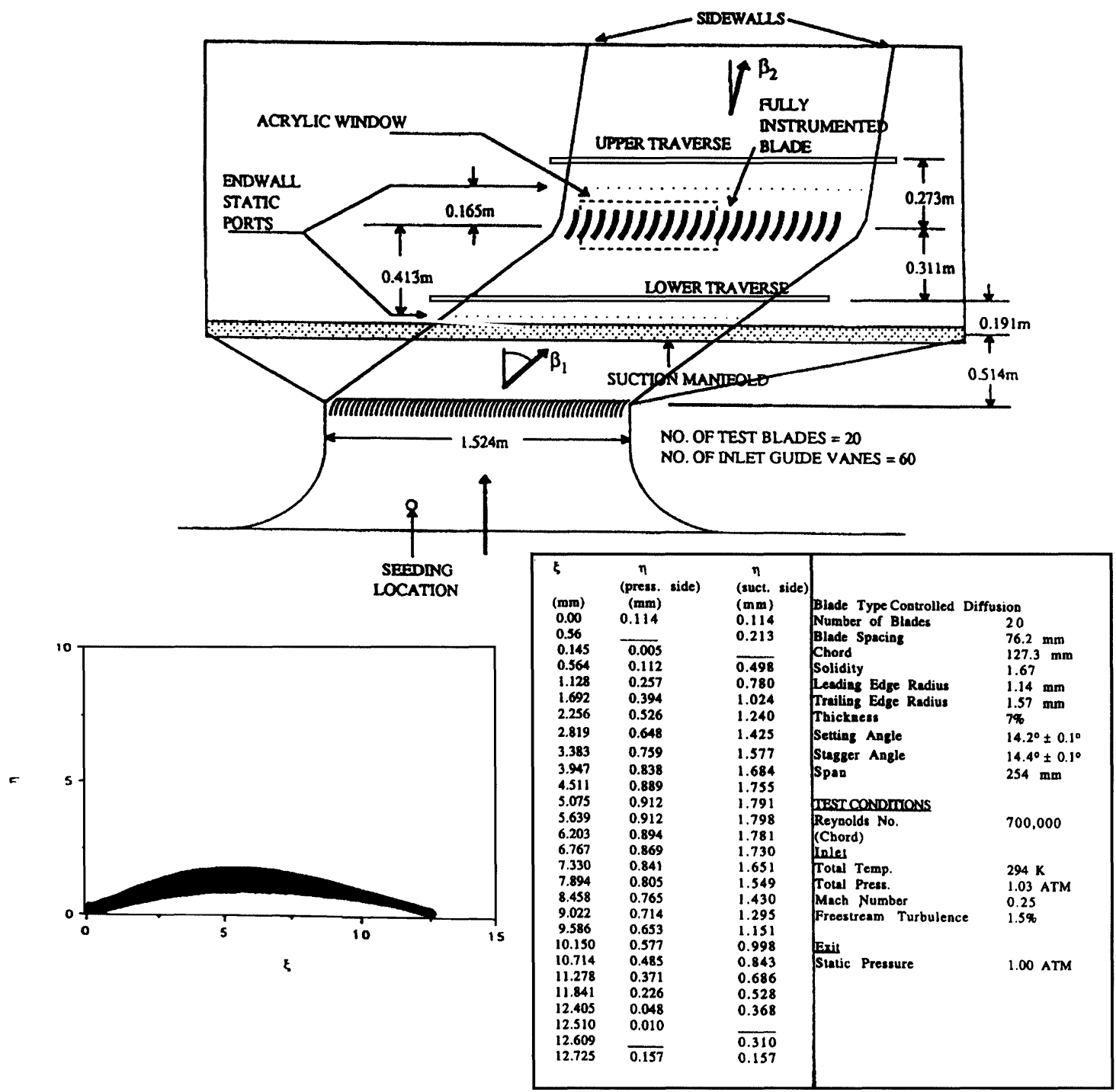

FIGURE 6 Schematic of the low speed cascade wind tunnel, controlled-diffusion compressor blade and test conditions.

edge of the blades $(2.17 \%, 1.10 \%$ and $0.57 \%$ axial chord ahead of the leading edges). The hot-film probe was positioned horizontally in the tunnel (i.e. in the tangential direction, with respect to the blades, with the sensor parallel to the spanwise direction) whilst traversing across the leading edges. This was done to ensure that there was no probe stem interference on the measured turbulence level as it was traversed past the leading edge.

\section{RESULTS AND DISCUSSION}

As can be seen from Figs. 7-9, the locus of points of maximum turbulence intensity, for all three inletflow angles considered, approaches the blade leading edge at right angles to the approaching stagnation streamline. The approximate location of the stagnation streamline is shown as the locus of points of minimum total velocity. Due to small blade setting angle errors $\left(<0.1^{\circ}\right)$ and the lack of 


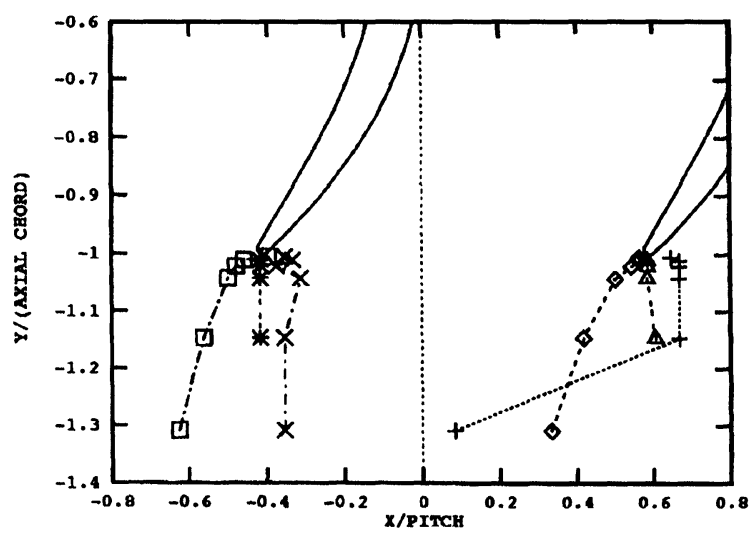

FIGURE $7 \quad$ Inlet-flow angle $=43.3 \mathrm{deg}$.

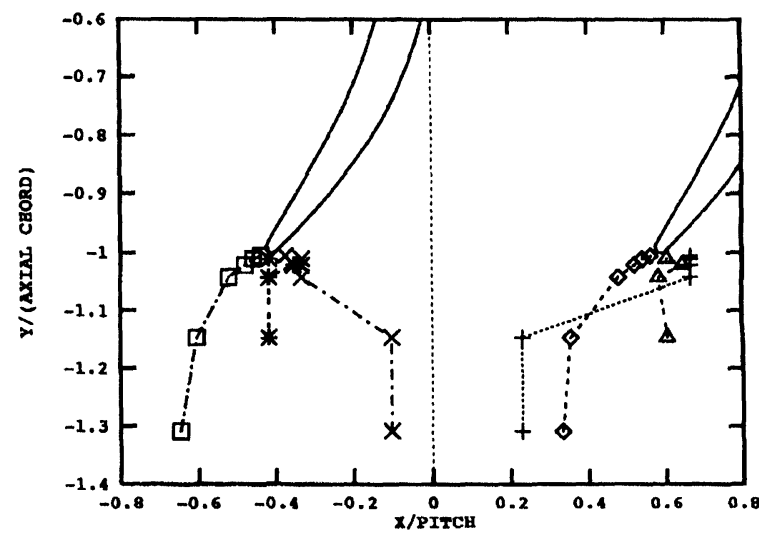

FIGURE 8 Inlet-flow angle $=46.4 \mathrm{deg}$.

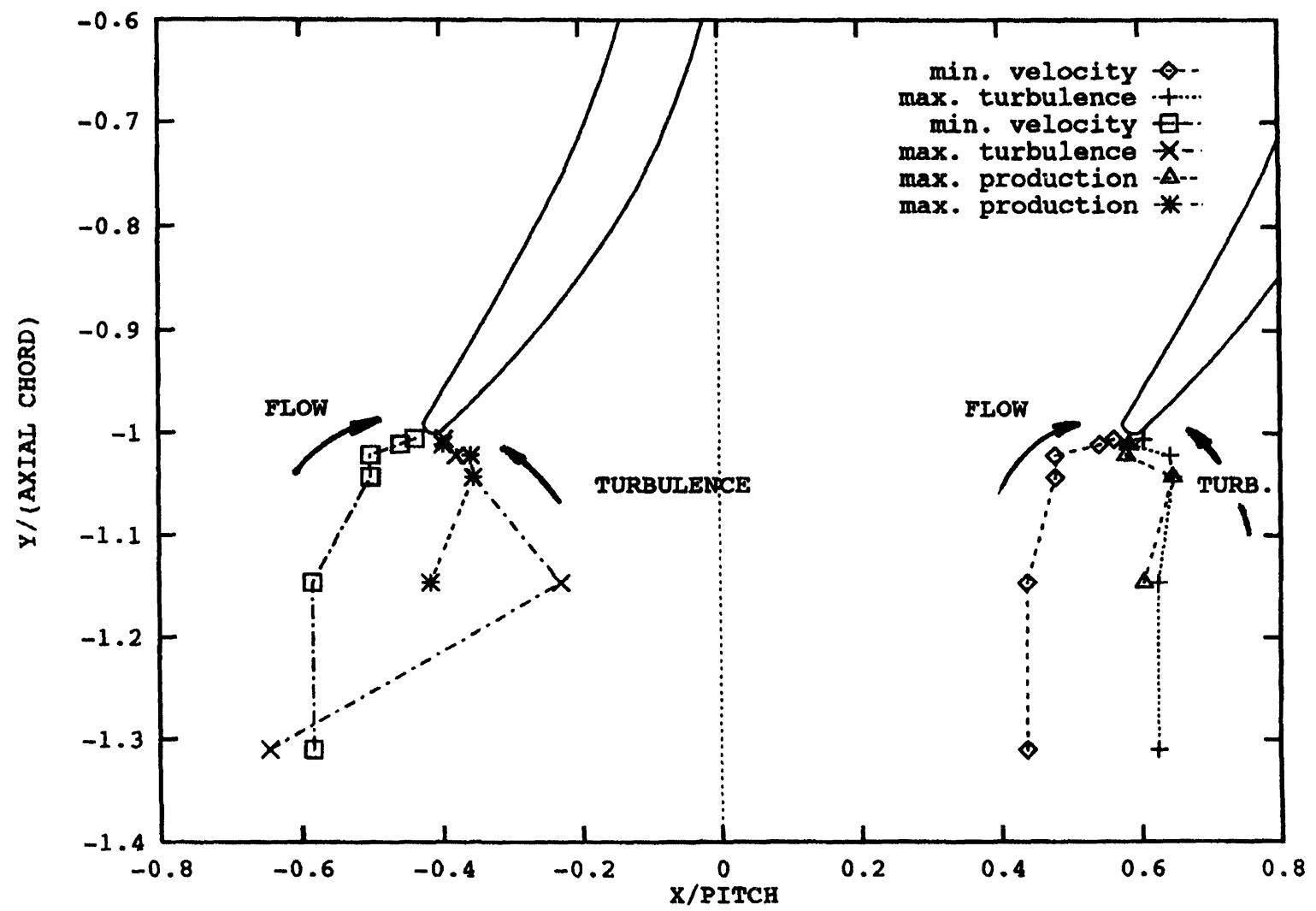

FIGURE 9 Inlet-flow angle $=48.4 \mathrm{deg}$. (Locus of points of min. total velocity, max. turbulence and max. turbulence production). 
perfectly two-dimensional inlet-flow there were small differences in trajectories of the maximum turbulence and minimum total velocity from blade to blade. However, the overall trend as the locus of points approaches the blades is periodic.

The increase in turbulence intensity, ahead of the blade leading edge, is not due to streamwise diffusion, but is caused by local shear as the flow attempts to accelerate around the leading edge. Local shear will produce turbulence, as is shown by the production term in the transport equation for turbulent kinetic energy (Hinze, 1975),

$$
\begin{aligned}
& \frac{\mathrm{D}}{\mathrm{D} t}\left(\overline{\frac{q^{2}}{2}}\right)=-\frac{\partial}{\partial x_{i}} \overline{u_{i}^{\prime}\left(\frac{p}{\rho}+\frac{q^{2}}{2}\right)}-\overline{u_{i}^{\prime} u_{j}^{\prime}} \frac{\partial \bar{U}_{j}}{\partial x_{i}} \\
& +\nu \frac{\partial}{\partial x_{i}} \overline{u_{j}^{\prime}\left(\frac{\partial u_{i}^{\prime}}{\partial x_{j}}+\frac{\partial u_{j}^{\prime}}{\partial x_{i}}\right)} \\
& -\nu \overline{\left(\frac{\partial u_{i}^{\prime}}{\partial x_{j}}+\frac{\partial u_{j}^{\prime}}{\partial x_{i}}\right) \frac{\partial u_{i}^{\prime}}{\partial x_{j}},}
\end{aligned}
$$

where the second term, on the right hand side, is the work by the viscous shear stresses of the turbulent motion or the production term.
A bi-cubic spline was fitted to the individual components of the LDV data in the pitchwise direction. This then allowed the differentiation of the measured velocity field, to determine each of the components of the two-dimensional production term

$$
\begin{aligned}
& \text { Prod. } \propto 2\left\{\left(\frac{\partial U}{\partial x}\right)^{2}+\left(\frac{\partial V}{\partial y}\right)^{2}+\left(\frac{\partial U}{\partial y}\right)\left(\frac{\partial V}{\partial x}\right)\right\} \\
&+\left(\frac{\partial U}{\partial y}\right)^{2}+\left(\frac{\partial V}{\partial x}\right)^{2} .
\end{aligned}
$$

The distribution of measured turbulence production is shown in Fig. 10 for $\beta_{1}=48.4^{\circ}$. A "ridge" of high turbulence production exists in the region ahead of the blades, at right angles to the stagnation streamline and parallel to the points of maximum turbulence intensity. The significant turbulent production is the reason for the increase in turbulence ahead of the blades, particularly at increasing incidence.

Next the actual increase in turbulence intensity along the line of maximum intensity is plotted for each of the three test cases (see Fig. 11). As can

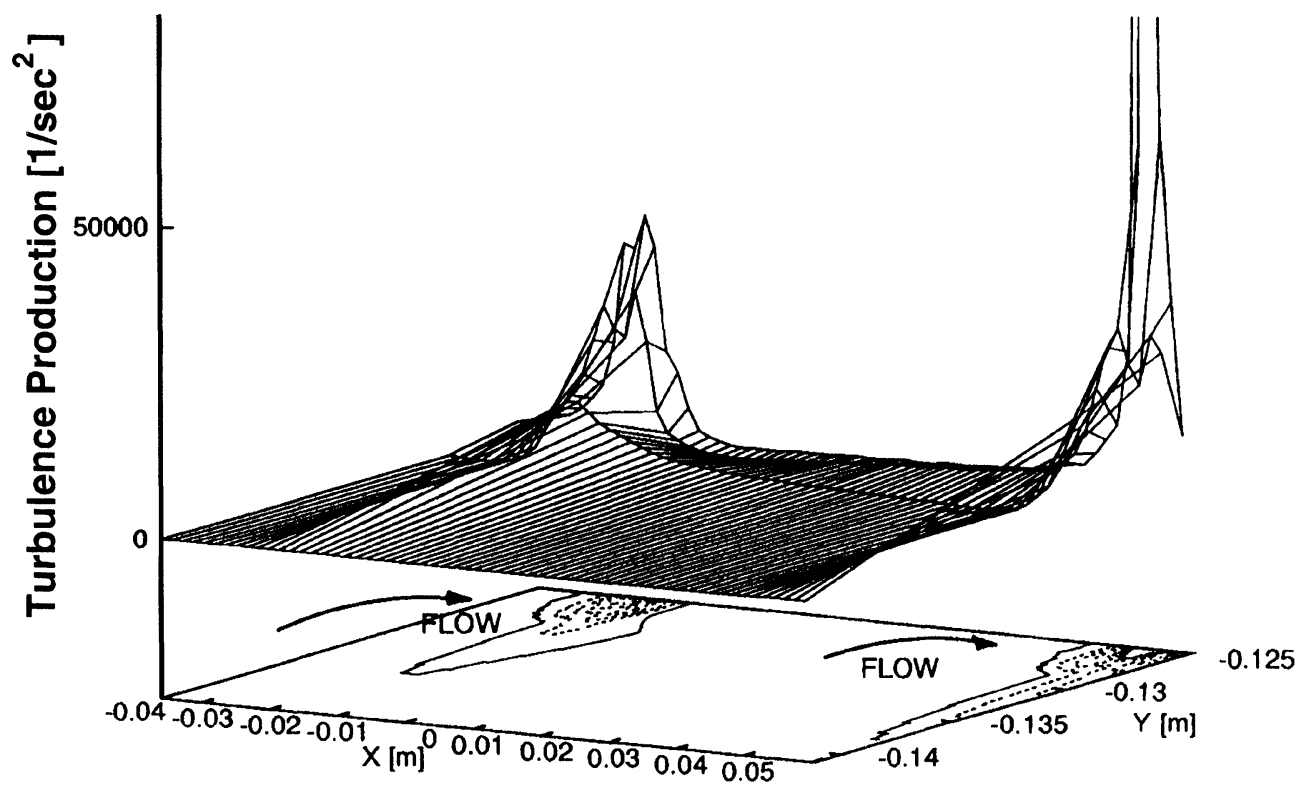

FIGURE 10 Upstream turbulence production for $48.4 \mathrm{deg}$. inlet-flow angle. 


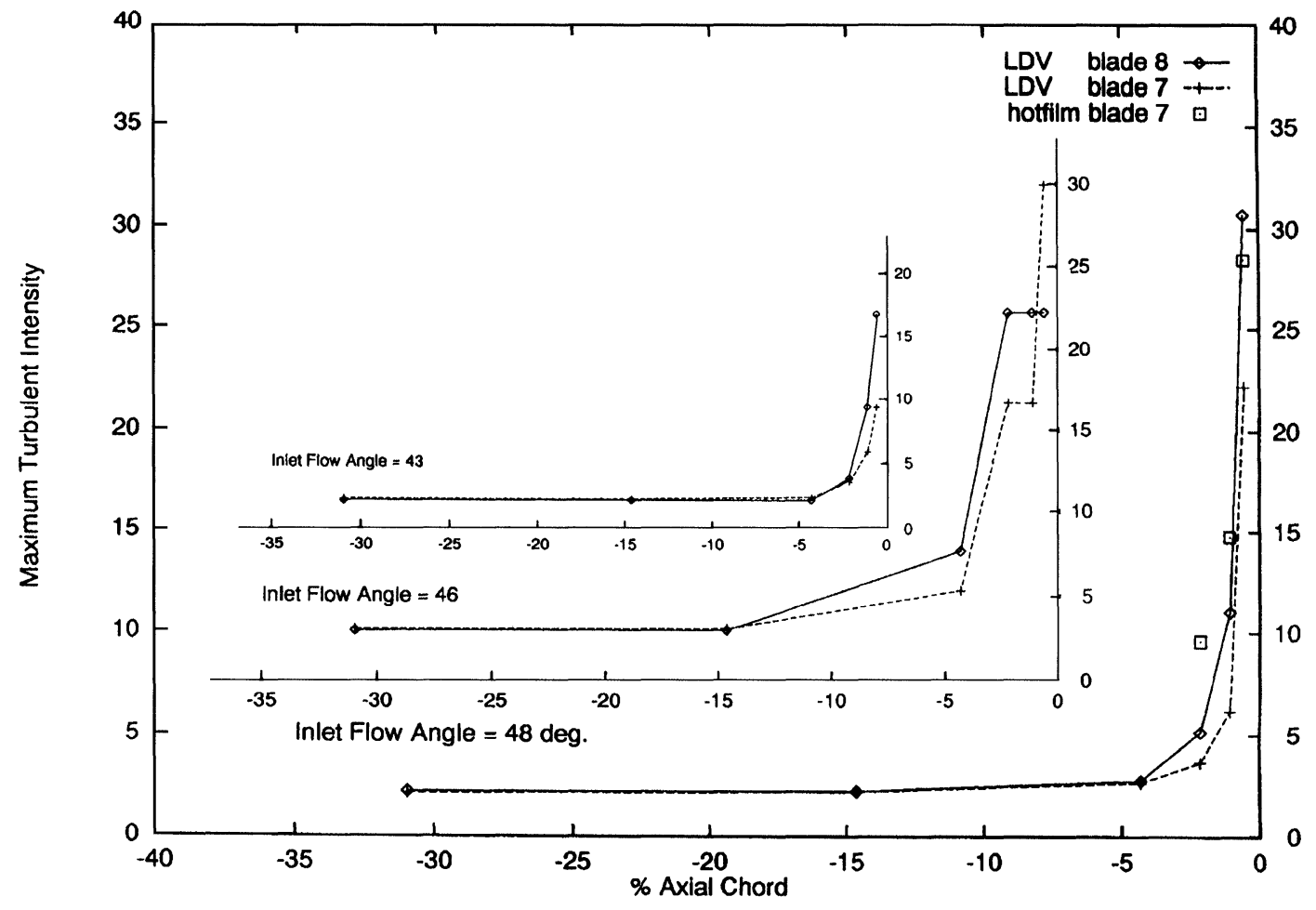

FIGURE 11 Maximum inlet turbulence intensity for varying inlet-flow angle.

be seen for all three test cases, the increase is exponential and highly localized around the leading edge. Note that the hot-film probe measurements verify the turbulence level measured by the LDV system.

Furthermore in Fig. 12 the maximum turbulence intensity as measured by the LDV is plotted for each of the three inlet-flow angles. Here the increase in maximum turbulence intensity is also seen to increase non-linearly, with increasing slope for increasing suction-side velocity gradient. Note that the trend of increasing turbulence intensity with increasing incidence is similar to that of the data match of Fig. 5. However, the data presented is from a surface flow visualization at lower Reynolds number, while that of Fig. 12 has been measured by both LDV and a hot-film approximately $1 \%$ of chord ahead of the leading edge.

Finally, the variation of turbulence intensity along the blade suction surface is given in Fig. 13 .

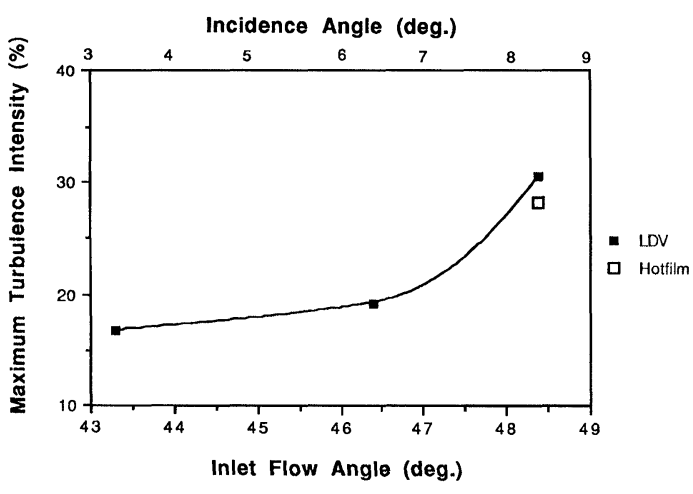

FIGURE 12 Maximum cascade inlet turbulence near the leading edge.

The values in this figure are LDV measurements taken in the freestream at the edge of the boundary layer at mid-span and plotted in the streamwise direction. It can be seen that the turbulent boundary layer downstream of the laminar bubble develops in an elevated turbulence intensity environment 


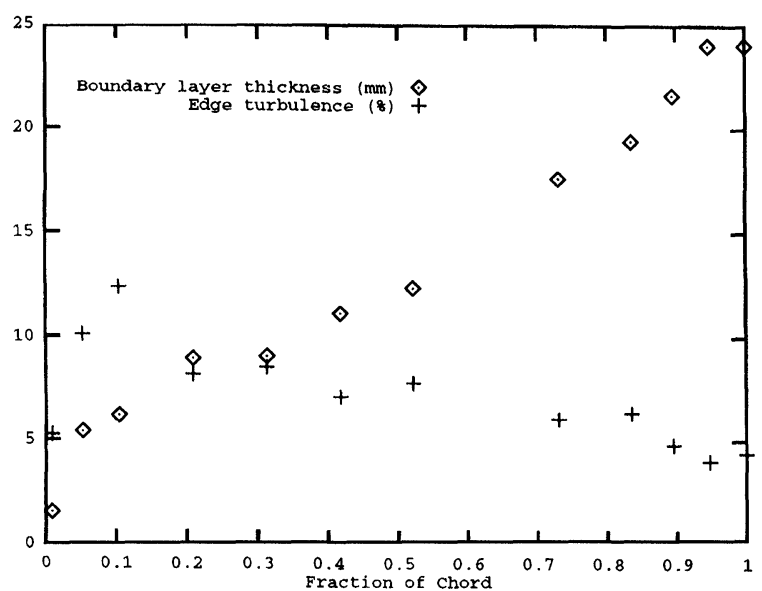

FIGURE 13 Boundary layer thickness and variation of edge turbulence on the suction side at $48.4 \mathrm{deg}$. inlet-flow angle.

that varies from approximately $12 \%$ near the leading edge to approximately $4 \%$ at the trailing edge. This is much higher than the inlet freestream value of $1.5 \%$ and this will have a significant effect on boundary layer development.

\section{CONCLUSIONS}

The experiments reported herein show that the freestream turbulence can be amplified greatly near the leading edge of a compressor blade at medium to high incidence angle. This increased turbulence level can have a strong effect on the boundary layer transition process, especially when conditions allow the formation of a laminar separation bubble.

The reasonable prediction of transition through a laminar bubble requires at least a reasonable assessment of the turbulence environment approaching the leading edge. For laminar bubbles occurring near the leading edge of compressor blades at high incidence, as well as the continued development of the turbulent boundary layer, the amplification of freestream turbulence should be taken into account in order to perform an accurate calculation of these flow phenomena. Also, the variation of elevated turbulence levels over the blade surface will affect boundary layer development downstream of the bubble and should be taken into account.
Finally, large scale experiments should be performed to better define the flow phenomenon of laminar bubbles and turbulence amplification at the leading edge suction surface of compressor blades at off-design incidence and over the downstream surfaces.

\section{NOMENCLATURE}

C chord length

$p$ pressure

$q^{2} \quad u_{i}^{\prime} u_{i}^{\prime}$, twice energy of turbulence

Re chord Reynolds number

$S$ distance along the chord

$\mathrm{Tu}$ turbulence intensity, $\sqrt{\overline{u^{\prime 2}}+\overline{v^{\prime 2}}} / V_{\text {ref }}$

$U$ tangential velocity

$u^{\prime} \quad$ tangential fluctuating velocity

$V \quad$ axial velocity

$v^{\prime} \quad$ axial fluctuating velocity

$V_{\text {ref }}$ upstream reference velocity, $\sqrt{U^{2}+V^{2}}$ upstrean

$V_{\text {tot }}$ local total velocity, $\sqrt{U^{2}+V^{2}}$

$x \quad$ tangential direction

$y \quad$ axial direction

$\beta_{1} \quad$ inlet flow angle

$\nu \quad$ kinematic viscosity

\section{Acknowledgments}

The authors would like to thank the Propulsion and Power Engineering group at the Naval Air Warfare Center (Trenton), and in particular Mr. Stoney MacAdams for his support of this research, which was funded as part of a Fan and Compressor Stall project. The last author would also like to thank the Turbopropulsion Laboratory of the Naval Postgraduate School for his support on this project.

\section{References}

Elazar, Y. and Shreeve, R.P. (1989) Viscous flow in a controlleddiffusion compressor cascade with increasing incidence, ASME Journal of Turbomachinery, 112(2), 256-266.

Gault, D.E. (1955) An experimental investigation of regions of separated flow, NACA TN 3505.

Hinze, J.O. (1975) Turbulence, Second Edition, McGraw-Hill. 
Hobson, G.V. and Shreeve, R.P.S. (1993) Inlet turbulence distortion and viscous flow development in a controlleddiffusion compressor cascade at very high incidence, $A I A A$ Journal of Propulsion and Power, 9(3), 397-407.

LeFoll, J. (1965) A theory of the representation of boundary layers on a plane, Proceedings of Seminar on Advanced Problems in Turbomachinery, von Karman Institute.

Martensen, E. (1959) Berechnung der Druckverteilung an Gitterprofilen in ebener Potentialströmung mit einer Fredholmschen Integralgleichung, Archives for Rational Mechanics and Analysis, Truesdell, 3(3), 235.
Roberts, W.B. (1975) The effect of Reynolds number and laminar separation on axial cascade performance, ASME Journal of Engineering for Power, 97A(3), 261.

Sanger, N.L. and Shreeve, R.P. (1986) Comparison of calculated and experimental cascade performance for controlled-diffusion compressor stator blading, ASME Journal of Turbomachinery, 108, 42-50.

Wakefield, B.E. (1993) Hotwire measurements of the turbulent flow into a cascade of controlled-diffusion compressor blades, Master of Science in Engineering Science. 


\section{ait \\ ENERGY MATERIALS}

M A N E Y publishing

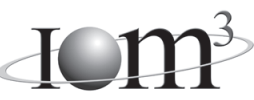

\section{Materials Science \& Engineering for Energy Systems}

Maney Publishing on behalf of the Institute of Materials, Minerals and Mining

The Institute of Materials, Minerals \& Mining

Economic and environmental factors are creating ever greater pressures for the efficient generation, transmission and use of energy. Materials developments are crucial to progress in all these areas: to innovation in design; to extending lifetime and maintenance intervals; and to successful operation in more demanding environments. Drawing together the broad community with interests in these areas, Energy Materials addresses materials needs in future energy generation, transmission, utilisation, conservation and storage. The journal covers thermal generation and gas turbines; renewable power (wind, wave, tidal, hydro, solar and geothermal); fuel cells (low and high temperature); materials issues relevant to biomass and biotechnology; nuclear power generation (fission and fusion); hydrogen generation and storage in the context of the 'hydrogen economy'; and the transmission and storage of the energy produced.

As well as publishing high-quality peer-reviewed research, Energy Materials promotes discussion of issues common to all sectors, through commissioned reviews and commentaries. The journal includes coverage of energy economics and policy, and broader social issues, since the political and legislative context influence research and investment decisions.

\section{CALL FOR PAPERS}

Contributions to the journal should be submitted online at http://ema.edmgr.com

To view the Notes for Contributors please visit: www.maney.co.uk/journals/notes/ema

Upon publication in 2006, this journal will be available via the Ingenta Connect journals service. To view free sample content online visit: www.ingentaconnect.com/content/maney

For further information please contact:

Maney Publishing UK

Tel: +44 (0)113 2497481 Fax: +44 (0)1132486983 Email: subscriptions@maney.co.uk

or

Maney Publishing North America

Tel (toll free): 8662975154 Fax: 6173546875 Email: maney@maneyusa.com

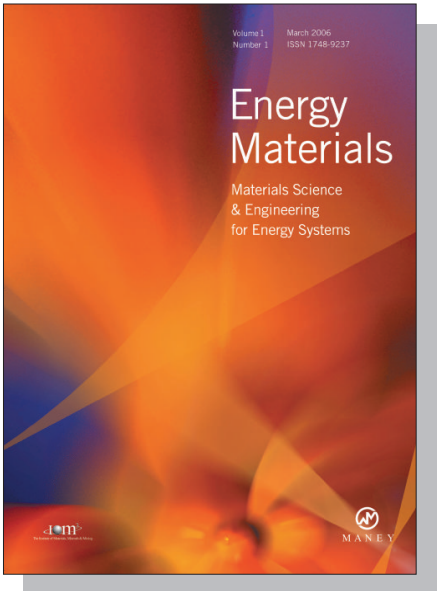

EDITORS

Dr Fujio Abe

NIMS, Japan

Dr John Hald, IPL-MPT, Technical University of Denmark, Denmark

Dr R Viswanathan, EPRI, USA

\section{SUBSCRIPTION INFORMATION}

Volume 1 (2006), 4 issues per year

Print ISSN: 1748-9237 Online ISSN: 1748-9245

Individual rate: $£ 76.00 / U S \$ 141.00$

Institutional rate: $£ 235.00 /$ US $\$ 435.00$

Online-only institutional rate: $£ 199.00 / U S \$ 367.00$

For special $\mathrm{IOM}^{3}$ member rates please email

subscriptions@maney.co.uk

\section{For further information or to subscribe online please visit www.maney.co.uk}



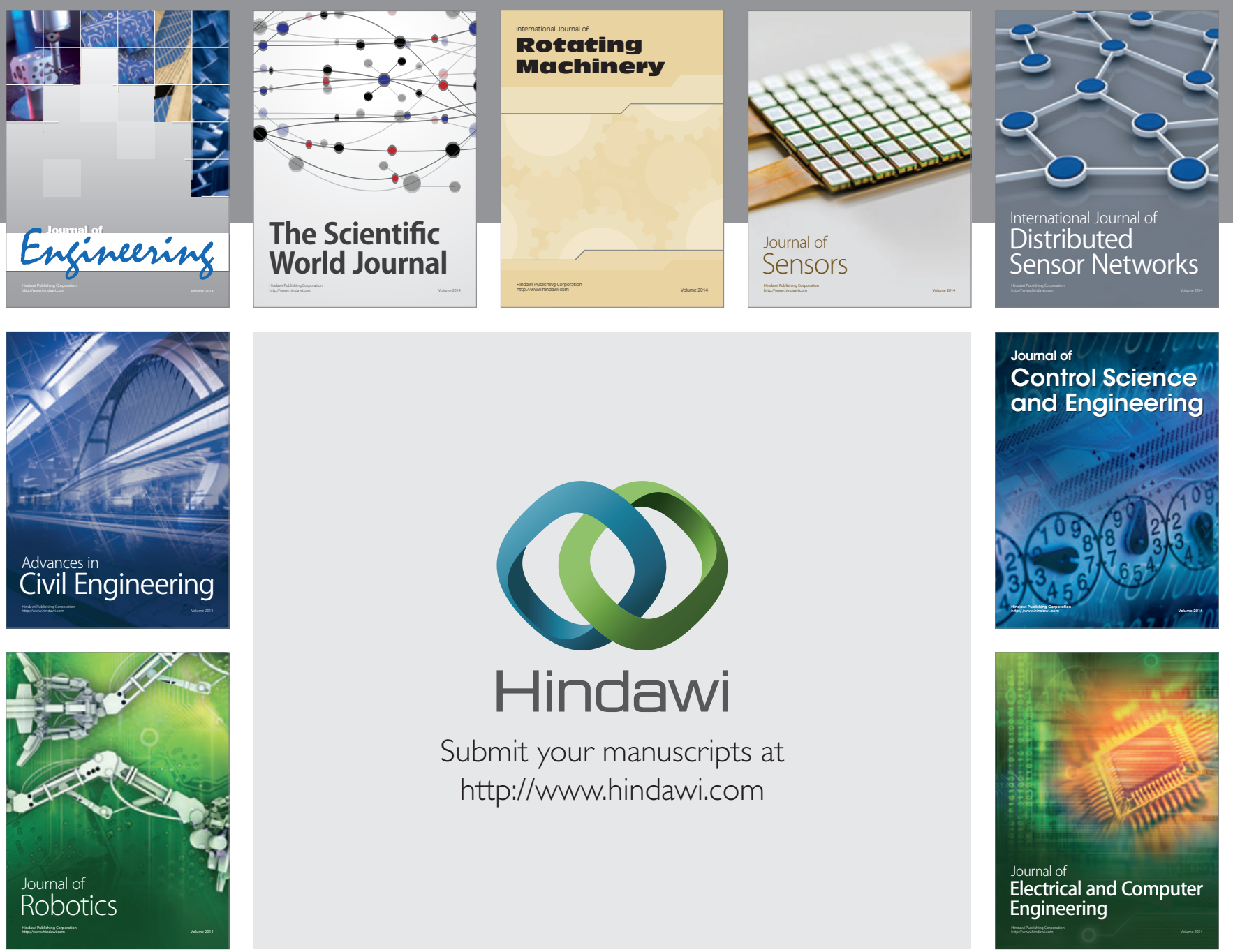

Submit your manuscripts at

http://www.hindawi.com
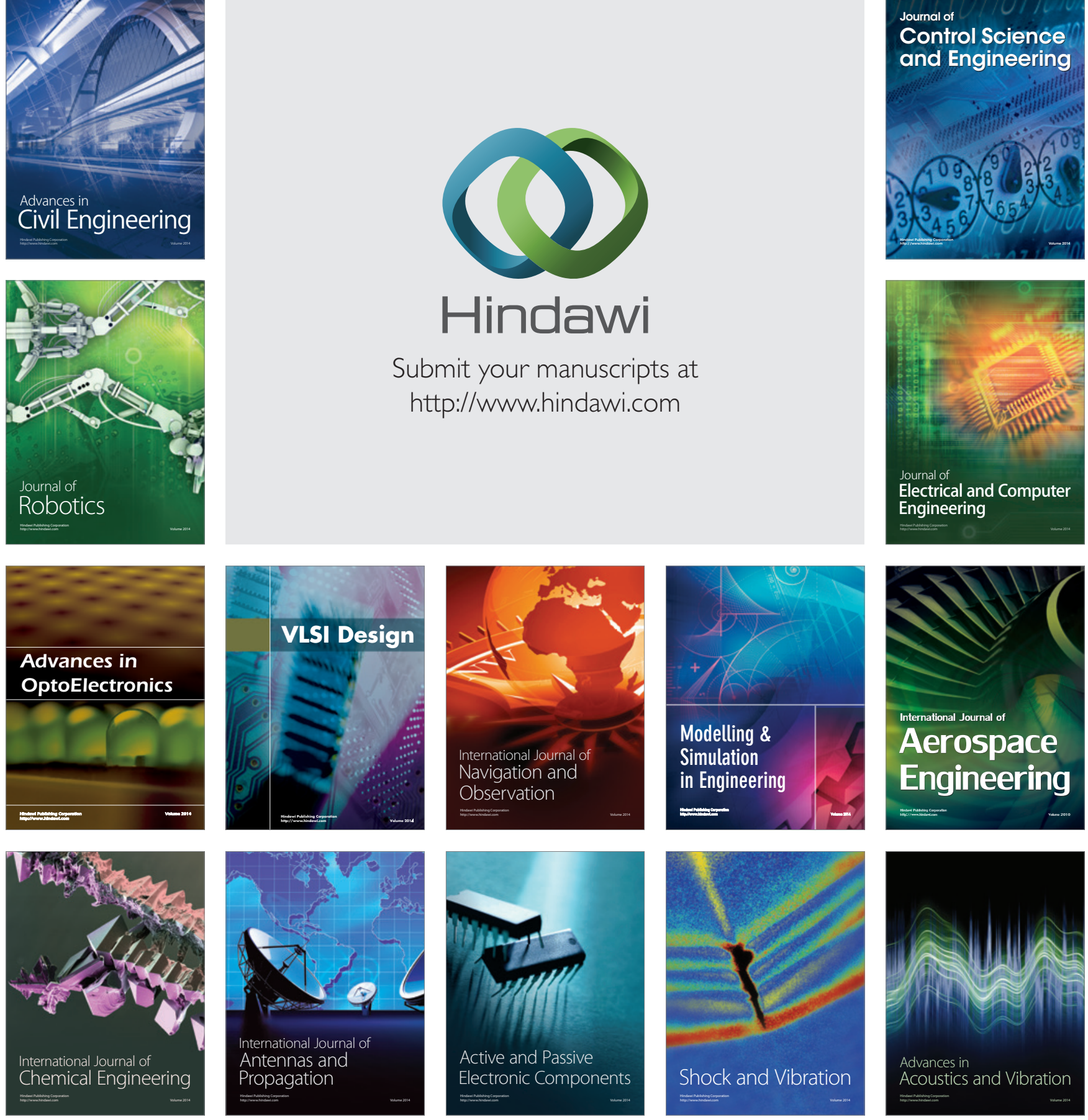